\title{
A ginástica artística masculina (GAM) de alto rendimento: observando a cultura de treinamento desde dentro.
}

Marco Antonio Coelho Bortoleto

Faculdade de Educação Física (Universidade Estadual de Campinas - Brasil)

Grupo de Pesquisa em Ginástica Geral (FEF - UNICAMP, CNPQ)

Grupo de Estudos Praxiológicos - GEP (Instituto Nacional de Educação Física da Catalunha - INEFC - Universidade de Lleida

- Espanhal

Bortoleto, M. A.; A ginástica artística masculina (GAM): observando a cultura de treinamento desde dentro. Motricidade 3(1): 323-336

\section{Resumo}

Este artigo apresenta um estudo etnográfico realizado no Ginásio de treinamento de Ginástica Artística Masculina do Centro de Alto Rendimento de Sant Cugat del Vallès (Barcelona Espanha). O objetivo principal desta pesquisa consistiu em desvelar as características principais da cultura de treinamento de uma sala de alto rendimento a partir de uma incursão de campo (de um ano e meio de duração) orientada pelos fundamentos teóricos da antropologia simbólica e dentro do marco metodológico da etnografia. Neste artigo destacamos o contexto institucional, alguns condicionantes temporais da preparação dos ginastas, aspectos da estrutura social do grupo, além de indicadores do universo simbólico que caracteriza a atividade no interior da sala. Entre as observações mais relevantes podemos destacar o Ginásio como uma microcultura caracterizada por várias cerimônias rituais, onde os técnicos tem o poder da palavra e os ginastas se limitam a escutar e intervir quando são solicitados (obedecer). Desta forma o funcionamento da sala se fundamenta no respeito à hierarquia de mandos e no cumprimento da programação das atividades e das regras.

Palavras-chave: Ginástica Artística Masculina (GAM), alto rendimento, cultura de treinamento, etnografia.

\section{Abstract}

Top level men artistic gymnastics (MAG): an observation of the training culture from the inside perspective.

This paper presents an ethnographic study that took place at a high level training gym of Men's Artistic Gymnastics, at the Olympic Training Center of Sant Cugat del Vallés (Barcelona Spain). The main goal of this study was to reveal the training culture characteristics of a high level training gym through a field observation (lasting one and a half year) by using the theoretical fundaments of the symbolic anthropology and the ethnographic methodology. We also highlight in this paper the institution context, some of the timing conditioning preparation of the gymnastics, some aspects of the social structure of the group and the universe symbolic indicators that characterize the activities inside the gym. Among the most relevant observation we detach the gym as a micro culture characterized by many ritual ceremonies, where the coaches have the power of the speech and the gymnasts are limited only to hear and execute whenever necessary. In this way the functioning of the gym follows a hierarchal respect of the orders and the responses of the activities and rules.

Keywords: Men's Artistic Gymnastics (MAG), high level, training culture, ethnography. 


\section{Introdução}

Como diriam alguns antropólogos, todo texto (lógica interna) possui um contexto (lógica externa) que lhe atribui sentido e significação ${ }^{1}$. Neste sentido a Ginástica Artística Masculina (GAM), enquanto prática esportiva de alto rendimento, se desenvolve em dois contextos distintos: a competição formal e a preparação para a competição (treinamento). Em função de suas características e necessidades particulares esta modalidade encontrou nos Ginásios o espaço idôneo para desenvolver o processo de treinamento que prepara os ginastas para a competição. De este modo, o Ginásio constitui o "contexto de treinamento" representando assim um lugar essencial para a evolução da GAM na sua vertente de alto nível ${ }^{2}$ que alberga grande parte dos saberes necessários para poder compreender este esporte desde uma perspectiva contextualizada, segundo descrevem Escalera in Medina e Sánchez ${ }^{3}$. Diferentemente do contexto competitivo, o de treinamento consiste uma realidade quase desconhecida, já que, além dos ginastas e técnicos, poucas são as pessoas que têm a oportunidade de conhecer seu funcionamento desde dentro.

Considerando o Ginásio como o contexto onde o ginasta se prepara para a competição, é imprescindível conhecer seu funcionamento em profundidade. Para conhecer esta realidade empreendemos uma descrição etnográfica das características mais representativas do funcionamento e da cultura de treinamento (ou de preparação) dos ginastas, no caso particular do Ginásio de GAM do Centro de Alto Rendimento (CAR) de Sant Cugat del Vallès, na província de Barcelona (Catalunha, Espanha). Uma sala onde treinam diariamente vários ginastas da seleção espanhola de alto rendimento, e que por tanto, possui alta representatividade tanto no âmbito nacional como no internacional.

Os resultados desta pesquisa elucidam parte da complexa cultura de treinamento da GAM, destacando alguns dos aspectos que influenciam na sua dinâmica. Além de representar um importante "feedback" para os próprios protagonistas também significam um primeiro passo para a realização de futuros estudos comparativos sobre distintos Ginásios, em diferentes localidades ou países, e seus modos particulares de preparar os ginastas.

Esta pesquisa justifica-se ademais pela escassez de antecedentes antropológicos no campo do esporte, especialmente sobre a GAM. A maior parte dos estudos realizados até o momento foram enfocados em modalidades massivas, como o futebol por exemplo, descrevendo principalmente problemas de grande impacto social como a violência e as questões de gênero.

Um marco importante para o desenvolvimento da Antropologia do Esporte foi a criação, em 1974, da "Associação Antropológica para o estudo do esporte e o jogo" ${ }^{4}$, precedida por um significativo incremento dos estudos sobre a violência no esporte, sobre a participação da mulher no esporte e os problemas de gênero, sobre os esportes de aventura, sobre os aspectos ecológicos do esporte, além da masculinidade, a política e o espetáculo esportivo, a etnicidade e a identidade gerada pelo esporte.

O futebol, maior expressão do fenômeno esportivo moderno, é a modalidade que mais atrai a atenção dos antropólogos. Por outro lado, o Boxe e o Rugby também vem sendo pesquisados a partir do enfoque sociológico-antropológico. Nesta área devemos fazer uma menção especial às 
obras de Joseph L.Arbena (org.) de 1988, titulada "Sport and Society in Latin America", de Jeremy MacClancy (ed.) de 1996, titulada "Sport, identity and ethnicity" e a recente publicação espanhola de 2003, titulada "Culturas en juego: ensayo de antropología del deporte en España"3. Além destas, queremos citar o "dossier" publicado em 1994 pelo Instituto Catalão de Antropologia sob a coordenação de Manuel Delgado, no qual aparecem textos muito interessantes de Vincenzo Padiglione, Norbet Elias e Daniel Denis; assim como a edição monográfica da revista francesa "Ethnologie Française" publicada em 1985 (n. ${ }^{\circ}$ 4), dedicada exclusivamente ao desporto.

Depois de realizar uma rigorosa revisão bibliográfica não encontramos antecedentes em antropologia do esporte sobre a GAM nem sobre os Ginásios de treinamento nesta modalidade. Apenas logramos acessar alguns estudos relevantes sobre esta temática: o primeiro sobre um Ginásio de boxe nos EUA ${ }^{22}$, outros dois sobre a cultura da Ginástica Rítmica na França ${ }^{30,32}$, um sobre a Ginástica Artística Feminina no Brasil ${ }^{34}$, e por último um sobre a cultura do Vôlei de praia na Espanha ${ }^{33}$.

\section{Metodologia}

Do ponto de vista da Antropologia Simbólica o Ginásio pode ser considerado uma microcultura com características peculiares, as quais podem ser descritas a partir do significado que seus próprios protagonistas lhes atribuem ${ }^{5}$. Para a descrição da cultura de treinamento optamos por um estudo etnográfico, método que segundo Rodríguez et al. ${ }^{6}$, permite conhecer "el modo de vida de una unidad social concreta", neste caso do Ginásio e de seus usuários. Conseqüentemente, realizamos uma viajem até o ambiente prático, através de uma pesquisa de campo ${ }^{7}$. Devido a escassez de antecedentes metodológicos tivemos que embasar-nos nos fundamentos metodológicos da etnografia aplicada ao contexto escolar, como por exemplo os oferecidos por $\mathrm{Ogbu}^{8}$, Wolcott ${ }^{9}$, Wil$\operatorname{cox}^{10}$, Woods ${ }^{11}$ e Woods ${ }^{12}$, e também em alguns modelos utilizados para o estudo de realidades socioculturais mais complexas ${ }^{13}$.

A presença no Ginásio se prolongou durante um ano e meio (2003-2004) aproximadamente, e permitiu utilizar vários procedimentos de coleta de dados, de acordo com as indicações de Rodríguez et al. ${ }^{6}$. Atendendo as orientações de André ${ }^{14}$, Mata $^{15}$ e Triviños $^{16}$ os dados necessários para a descrição foram obtidos consultando diferentes fontes:

- Documentos escritos: Projeto de tecnificação da Federação Catalana de Ginástica (FCG); Programa anual de treinamento; Normativas de condutas para os residentes e usuários do CAR de Sant Cugat; Texto introdutório sobre o CAR; etc.;

- Testemunhos orais dos ginastas, técnicos e outros protagonistas: oito entrevistas gravadas em cassete;

- Observação participante das atividades cotidianas do Ginásio: 70 sessões, com um total aproximado de 300 horas de observação registradas num diário de campo;

Imagens: aproximadamente 100 fotografias realizadas periodicamente durante as distintas fases da pesquisa, acompanhando a evolução dos períodos de treinamento.

Tendo em conta a complexidade implícita em todo estudo etnográfico, os limites temporais e os objetivos da tese de doutoramento que originou este artigo e fundamentalmente os limites espaciais desta publicação, decidimos delimitar a descrição da cultura de treinamento concentrando nossa atenção nas seguintes dimensões e indicadores:

a) o Ginásio como instituição; 
A ginástica artística masculina (GAM) de alto rendimento: observando a cultura de treinamento desde dentro.

Marco Antonio Coelho Bortoleto

\section{Resultados}

b) os imperativos temporais da preparação ginástica;

c) o mundo social do Ginásio (os ginastas);

d) o mundo simbólico do Ginásio (o Ginásio como um templo amorosiano).

A análise dos dados foi realizada, segundo o critério que define Geertz ${ }^{17}$, ou seja, como um "ato de estranhar o comum e aceitar o estranho". Considerando que "el análisis de datos es visto por algunos como una de las tareas de mayor dificultad en el proceso de investigación cualitativo" buscamos ser altamente rigorosos nesta fase da pesquisa ${ }^{6}$ respaldando-nos em diferentes procedimentos de validação e certificação (triangulação de especialistas, revisão dos próprios sujeitos implicados, etc.). O processo analítico-interpretativo utilizado foi dividido nas seguintes etapas: a) leitura inicial; b) transcrição das notas de campo e entrevistas; c) redução do texto e categorização dos dados; e d) redação do relatório final.

Como acontece normalmente nos estudos desta natureza, a análise não foi um procedimento posterior à coleta de dados, muito menos estático. Durante todo o desenvolvimento da pesquisa de campo fomos confeccionando o texto descritivo, somando ao seu conteúdo às informações que conseguimos e aperfeiçoando diariamente este texto a partir de uma compreensão mais aprofundada dos sucessos. Depois de um ano de observações, e motivados pelas férias dos esportistas, redigimos uma versão preliminar do texto descritivo, a qual foi submetida a uma revisão e avaliação dos orientadores da tese e também de um consultor externo especialista em GAM. Posteriormente, retomamos as observações de campo para clarificar os aspectos ainda confusos da pesquisa e completar alguns temas que ainda estavam escassos de dados. Esta última visita ao cenário nos permitiu elaborar a versão final do texto descritivo com maior riqueza de detalhes.
O Ginásio como instituição

A atividade no interior do Ginásio atende às diretrizes que seu contexto institucional, ou seja, seu funcionamento está rigidamente regulado pelas estruturas sociais e suas respectivas leis, políticas, valores morais e éticos (imagem 1).

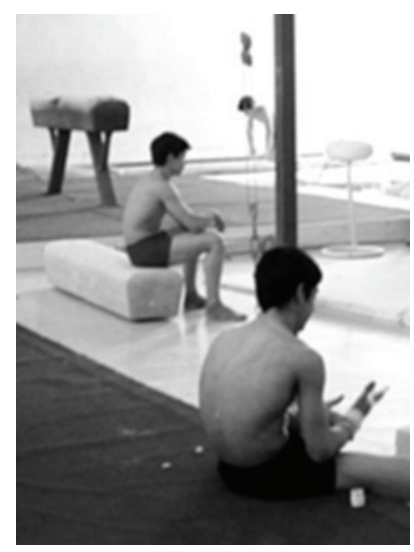

Imagem 1. Ginastas descansando.

Do ponto de vista legal, em 1968 o governo espanhol editou o "Plan ideal de apoyo al desarrollo de la actividad deportiva", segundo resenham García Ferrando et $\mathrm{al}^{4}$. Em 1978, o Conselho Superior do Esporte (CSD) criou o plano de tecnificação para o esporte de alto nível, medida que deu origem à construção dos Centros de Alto Rendimento (CAR), além de outros centros menores destinados ao esporte de competição. No entanto, foi com o artigo de lei "ok10/1900" que o governo deste país definiu as competências e responsabilidades dos Centros de Alto Rendimento e a possibilidade do apoio dos governos estaduais (autonômicos) a estas instituições, impulsionando as atividades neste setor. $\mathrm{Na}$ atualidade apenas dois Centros de Alto Rendimento, o de Madrid e o de Sant Cugat, oferecem treinamento em GAM. Particularmente 
o CAR de Sant Cugat, onde desenvolvemos nosso estudo (imagem 2), iniciou suas atividades em 1987, no entanto sua inauguração oficial somente foi realizada em novembro de 1990. Definido como uma empresa que presta serviços na área do esporte de alto nível o CAR de Sant Cugat possui uma organização e administração própria, além de autonomia jurídica. Este centro está vinculado aos organismos públicos por meio do Conselho Executivo da Catalunha e da Secretaria de Educação deste estado. Esta instituição se mantém com o dinheiro de patrocínios, ajudas econômicas de fundações, da propaganda de algumas empresas além da ajuda da Secretaria Geral do Esporte da Catalunha (SGE) e do Conselho Superior do Esporte (CSD). A pesar de possuir um estatuto legal próprio segue as normativas políticas do Conselho Catalão do Esporte, órgão de maior autoridade esportiva no estado, estabelecendo como objetivo principal a formação de esportistas de alto nível, pondo ao ser serviço os melhores meios materiais, técnicos, pedagógicos, científicos e humanos necessários e disponíveis, além de velar sempre por sua formação integral e por transmitir à sociedade os conhecimentos gerados por estas atividades ${ }^{35}$.

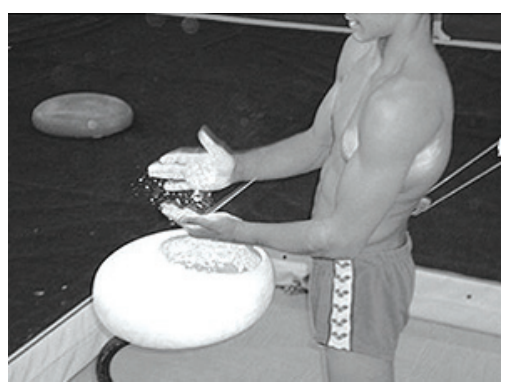

Imagem 2. Ginasta colocando magnésio nas mãos.

O CAR de Sant Cugat está dividido em quatro unidades básicas: unidade técnica: instalações e coordenação de técnicos; unidade de direção e administração; unidade acadêmica: escola e tutoria; unidade de pesquisa: controle médico, acompanhamento e processos de treinamento, psicologia, biomecânica, nutrição-fisiologia, fisioterapia e desenvolvimento de projetos de pesquisa. Suas instalações o convertem no maior centro de treinamento esportivo da Catalunha, especializado em esportes individuais, que acolhe aproximadamente 500 esportistas, sendo 300 em regime de internato na sua própria residência. Seu funcionamento está a cargo de uma equipe de 150 profissionais. Este centro está estrategicamente situado fora de Barcelona e ao mesmo tempo perto deste grande centro urbano (capital do estado) facilitando assim o acesso ao transporte (aeroporto, estações de trem, rodovias) e aos grandes centros sanitários (hospitais).

O CAR concentra um grande número de pessoas com um objeto comum, pessoas que compartilham diferentes faces da vida, como a acadêmica (estudos), residência e atividades de lazer-recreação. Esta mesma instituição trata de regular seu funcionamento e o comportamento de seus usuários a partir de uma normativa de conduta (regras) própria. Por conseguinte, com o decorrer do tempo este centro passou a gerar um grande sentimento de pertinência e de amizade entre seus usuários, uma identidade comum, um sentimento de associacionismo ou de "coletividade social", circunstâncias que nos permitem, do ponto de vista antropológico, tratar esta instituição como uma "comunidade".

Sobre a temporalidade do treinamento

A preparação dos ginastas obedece uma temporalidade específica. Nos referimos, em primeiro lugar, a umas condições de tempo que podem ser expressas da seguinte maneira: uma jornada diária de duas sessões, totalizando 5-6 horas de treinamento, seis dias por semana e aproximadamente 300 dias ao ano. Trata-se de uma dedicação altamente absorvente interrompida 
A ginástica artística masculina (GAM) de alto rendimento: observando a cultura de treinamento desde dentro.

Marco Antonio Coelho Bortoleto

por dois períodos de férias (descanso) de 15 dias aproximadamente durante todo o ano, que apenas permitem realizar outras atividades, como por exemplo, estudar, estar com a família, ver os amigos ou passear. Com uma perspectiva mais ampla, podemos esboçar o "ciclo vital" (termo inspirado nos escritos de Husserl) do ginasta, um marco temporal que ajuda a entender a carreira esportiva típica de este esporte. Este processo de preparação dos ginastas normalmente começa no CAR ao redor dos 11-12 anos, no entanto a prática da GAM se inicia anteriormente nos clubes catalães por volta dos 7-8 anos. Um itinerário esportivo que pode estender-se ao longo de aproximadamente 13 anos, finalizando aos 25 anos na media. Além disso, vimos que para lograr resultados expressivos no âmbito de alto rendimento esportivo os ginastas podem esperar até 10 anos. Em sumo, o treinamento é um longo período no qual se intercalam muitos momentos difíceis, como lesões e/ou derrotas, e no qual somente uns poucos chegaram ao final com o êxito esperado. Uma rigorosa disciplina marcada pelo cansaço, mas que todos insistem em dizer que são conscientes das dificuldades e são felizes a pesar de tudo isso.

Ao mesmo tempo, ao presenciar os treinos entendemos que a atividade realizada na sala acontece de forma lenta e pausada, formando uma rotina cotidiana de repetições, milhares de repetições, sem a menor pressa (ao menos aparentemente), porém que devem cumprir os objetivos (programa) de cada uma das sessões. Este ritmo "lento" do treino tem um significado claro: todos sabem que estão imersos em um processo longo, de vários anos e qualquer falho pode atrapalhar os planos a longo prazo, por isso é importante treinar com calma, com muita paciência e dar o tempo necessário para que o corpo assimile as informações. Também dizem que este clima de tranqüilidade e aparente lentidão propicia um treino seguro e controlado e permite que o corpo técnico controle detalhadamente tudo que acontece na sala, evitando acidentes ou falhos durante o processo de aprendizagem.

Diariamente os ginastas se intercalam nos aparelhos realizando cada um os exercícios que seu técnico solicitou. Entre cada repetição aproveitam para descansar e sutilmente para conversar ou para fazer algum comentário sobre os exercícios. Evidentemente, mostrar-se cansado (deitando no chão por exemplo), falar alto, brincar, reclamar ou descansar muito tempo não são comportamentos bem vistos na sala. Por isso, todo mundo trata de respeitar de forma estrita o pacto oral que regula a dinâmica de funcionamento da sala.

A utilização dos aparelhos é planejada com antecedência pelos técnicos para que os diferentes grupos de ginastas não usem os mesmos setores (ou aparelhos) da sala de forma simultânea. No entanto, nem sempre é possível evitar este contato. Quando acontece, os ginastas mais velhos têm prioridade para usar. Todos dizem que esta aproximação é positiva pois permite por um lado aos ginastas mais novos aprender dos mais velhos. Ao mesmo tempo destacam que estas situações podem provocar uma diminuição do ritmo de treino (mais conversa, mais tempo de descanso, etc.). Eventualmente os ginastas mais velhos reclamam que os mais novos atrapalham seu treinamento, e reciprocamente os mais novos dizem que de vez em quando os mais velhos zombam deles. Estes conflitos raramente são notados, pois a tranquiilidade deve imperar na sala, e quando algo não funciona bem os técnicos tratam de intervir e chamar a atenção dos ginastas.

\section{A estrutura social do Ginásio}

Observando o fluxo cotidiano de pessoas na sala constatamos, em primeiro lugar, a existência de um grupo de 24 protagonistas "oficiais", ou seja, pessoas que freqüentam diariamente o Ginásio 
com um compromisso declarado com o centro e com a Federação Catalana de Ginástica (FCG). Por outra parte, a sala recebe a visita quase diária de outras pessoas, como por exemplo funcionários, ex-ginastas, visitantes do centro, amigos e também das ginastas e os técnicos (as) de GAF que treinam na sala ao lado. Quantificar com precisão este fluxo de pessoas era uma tarefa complicada e nos conformamos em saber que freqüentam a sala diariamente entre 25 e 30 pessoas, e que centramos a atenção no grupo regular.

O grupo dos ginastas está formado por 19 atletas com idades compreendidas entre 12 e 26 anos. Um coletivo de jovens, com um ideal (objetivo) comum e que optaram de forma precoce e "voluntariamente" por uma vida dedicada ao treinamento de alto nível. Em termos de Caillois in Lüschen e Weis ${ }^{18}$, a opção voluntária pela prática significa, ao menos em teoria, que estas pessoas podem decidir livremente o momento em que desejam interromper sua atividade esportiva. Esta liberdade é cada vez menor no esporte profissional, dado que se controla as decisões dos esportistas mediante contratos e penalizações federativas ou econômicas.

Por outra parte, o corpo técnico está formado por três técnicos, um auxiliar técnico e um psicólogo, profissionais que, exceto no caso do psicólogo, estão contratados diretamente pela FCG. Os técnicos são os que possuem o maior grau de proximidade com os ginastas e, além de cumprir com seu labor técnico, atuam como maestros-orientadores a nível pessoal, adquirindo um laço profundo de intimidade e amizade com os ginastas. Coincidimos com Anzieu e Martín ${ }^{19}$ quando afirmam que os técnicos representam os líderes do grupo e carregam com toda a responsabilidade de tomar as decisões mais importantes para a preparação dos ginastas.

Os 19 ginastas representam o coletivo mais numeroso. Deles, 17 estão oficialmente incorporados às atividades da sala e os outros dois se encontram em processo de incorporação. Os ginastas incorporados estão subdivididos em quatro categorias de idade: infantis (5), juvenis (4), juniores (3) e seniors (5). Segundo contaram os técnicos, esta classificação por franjas etárias obedece as normativas de competição da FCG, assim como da RFEG e da FIG. Conforme a "Normativa técnica de GAM" da Real Federação Espanhola de Ginástica, as categorias competitivas são: "benjamín” (10 anos ou menos), "alevín" (11 e 12), infantil (13 e 14), juvenil (15 e 16),junior (17 e 18) e senior (19 ou mais). A divisão dos membros do grupo por faixa etárias pode ser considerada um aspecto comum a todas as sociedades, facilitando a atribuição dos papéis, sua função no grupo e seu grado hierárquico. No caso do esporte, particularmente da GAM, esta divisão busca igualar as condições das competições em virtude das diferenças de rendimento respeito al desenvolvimento corporal. Além disso, pretende estabelecer normativas específicas para cada grupo evitando excessos por parte dos técnicos e das federações, segundo destaca a Federação Internacional de Ginástica ${ }^{20}$.

Os ginastas infantis são os mais jovens do grupo e, por conseguinte, os que se incorporaram mais recentemente. Têm entre 12 e 13 anos e apesar de serem novatos na sala, todos possuem uma anterior experiência de treino de GAM em clubes catalães, com uma média de 5 anos (3-7 anos) de prática. Segundo a obra de Leglise ${ }^{21}$, os ginastas acostumam iniciar a prática da GAM ao redor dos 5-7 anos de idade, coincidindo com o que observamos no CAR. Começaram a treinar no CAR há dois de média (1-4 anos), o que indica que se incorporaram em anos distintos. Os quatro ginastas juvenis têm entre 14 e 15 anos, e uma média de 10 anos praticando ginástica, sendo os últimos 3 no CAR. Os três ginastas juniores têm entre $16 \mathrm{e}$ 17 anos, estão treinando há 9 anos de média, sendo os últimos 4 no CAR. Os ginastas destes três gru- 
A ginástica artística masculina (GAM) de alto rendimento: observando a cultura de treinamento desde dentro.

Marco Antonio Coelho Bortoleto

pos conformam o que se denomina na sala "os menores" (mais novos em espanhol) ou, em ocasiões, os "pequenos". O emprego destas expressões não agrada aos ginastas juniores, porque neste faixa etária os jovens se identificam (ou assim querem que pareça) mais com os seniores que com os mais jovens (infantis e juvenis). Fato que revela uma fase de transição de categoria competitiva e também de atitudes e idéias.

Os cinco ginastas seniores, denominados pelo grupo de "mayores" (mais velhos) ou "adultos", têm entre 18 e 26 anos e treinam ginástica de oito a 20 anos, com 10 anos de média (8-12) no CAR. Por último, os dois ginastas em processo de incorporação pertencem à categoria infantil, e têm entre 12 e 13 anos de idade respectivamente.

Este reduzido número de ginastas indica, por um lado, a necessidade de manter o Ginásio com uma densidade populacional relativamente baixa, que facilita o controle exaustivo das atividades e que reflete um modelo de treinamento freqüentemente utilizado pelos países onde não existe tanta tradição ginástica (volumem de praticantes), nos quais os organismos reguladores e os responsáveis buscam extrair o melhor resultado possível dos poucos ginastas que conseguem ser admitidos nos programas de alto rendimento. Ademais, este fator demonstra indiretamente a dificuldade que existe na atualidade catalana e espanhola de captar ginastas com o potencial para treinar neste Ginásio, a pesar de sua excelente infra-estrutura.

Todos os ginastas foram selecionados pela FCG e, ao menos de momento, não existe nenhum treinando de forma independente, ou seja, pagando ao CAR para poder usar as instalações, a pesar de que o regulamento da instituição permita este tipo de atividade. Estes ginastas que treinam no CAR continuam representando seus clubes de origem nas competições estaduais ou inter-clubes. A política atual da FCC inclui ajudas econômicas (bolsas simbólicas) aos clubes por cada ginasta aportado ao CAR, reconhecendo de alguma forma sua importância no processo de formação de base (iniciação) da GAM e na captação de novos ginastas no âmbito escolar.

Dado os limites deste artigo os detalhes da formação e experiência dos profissionais que formam o corpo técnico não foram incluídos ${ }^{29}$. Todos os técnicos trabalham diariamente na sala, tanto na sessão da manhã como pela tarde. A pesar de que desde o primeiro dia de sua incorporação na sala os técnicos tentem preparar os ginastas para que sejam capazes de treinar de forma autônoma e seguindo estritamente o programa, sua presença é imprescindível. No caso de que um dos técnicos não possa estar presente um dos seus companheiros assume a responsabilidade do seu grupo de ginastas, mantendo as atividades planejadas pelo técnico original. Em poucas oportunidades presenciamos a ausência de um dos treinadores, no entanto, nos momentos que isso ocorreu a aparente autonomia dos ginastas se demonstrou frágil e relativa. Esta dificuldade em treinar de forma autônoma contraria o discurso dos técnicos e dos demais membros do corpo técnico. Talvez este seja um dos aspectos que deveriam ser melhorados na dinâmica de treinamento. Tomando emprestadas as palavras de um ginasta junior:

"Entrenar con nuestro entrenador es mucho mejor, sin él es diferente. Con él nos sentimos más orientados, aunque conocemos muy bien la planificación, aquella que está colgada en el tablón. Además, él está para cobrar empeño, marcar los fallos, así que particularmente prefiero que esté presente."

Em suma, a estrutura social do Ginásio está organizada hierarquicamente e nela todos sabem exatamente o papel de devem desempenhar, assim como seus poderes, deveres, responsabilidades, etc.

O mundo simbólico: o Ginásio como um templo amorosiano 
Da mesma maneira que muitos estádios de futebol são considerados espaços sagrados pelos jogadores e/ou torcedores, segundo afirma Morris ${ }^{23}$, o Ginásio é considerado pela maior parte de seus usuários um "santuário" ou um "território sagrado". O conceito de "santuário" não pode ser confundido com o utilizado por Wacquant ${ }^{22}$, apesar de que, de certa forma o Ginásio de GAM também funciona como um lugar de "pacificação e proteção" tratado com respeito por seus usuários.

Para entender esta concepção, devemos refletir sobre a origem dos Ginásios, momento em que estes lugares eram "proibidos" para a maior parte da população, um espaço que reunia os militares e a aristocracia civil e que agora alberga a elite esportiva. Neste sentido, a sociedade vê com "admiração" aqueles que logram entrar no interior dos Ginásios de treinamento, seja como guerreiros nos séculos anteriores ou como esportistas na atualidade, pois se convertem em representantes da nação e alguns deles chegam a atingir status de ídolos sociais, como comenta Padiglione $^{24}$. Além disso, a sala é sagrada porque representa um espaço fundamental para o desenvolvimento da GAM e também para a vida de seus protagonistas (espaço onde passam a maior parte de seu tempo), um lugar respeitado por seus usuários como se fosse sua própria casa.

A sala é freqüentada quase exclusivamente pelos ginastas e pelo corpo técnico, um lugar de difícil acesso a qualquer outra pessoa que não pertença a este coletivo. Trata-se de um lugar que representa um ícone para a GAM catalana e espanhola, um refúgio para a elite deste esporte, um espaço destinado a uns poucos privilegiados e ao que muitos desejam poder incorporar-se. Uma sala localizada dentro de uma instituição de referência internacional, como é o caso do CAR de Sant Cugat, e que conseqüentemente possui um status privilegiado no contexto ginástico espan- hol. Um espaço "fechado", "semi-público" por limitar o acesso de pessoas alheias, protegido do mundo exterior tanto arquitetonicamente como política e simbolicamente, impregnado por um peculiar cheiro de magnésio, repleto de aparelhos ginásticos oficiais e alternativos destinados única e exclusivamente à preparação dos esportistas. Uma "bolha" ("burbuja" em espanhol), conforme relatam seus próprios protagonistas, que durante longos anos "isola" estas pessoas buscando dar a tranqüilidade e a intimidada necessária para alcançar seu grande objetivo: a forja de campeões.

"El Gimnasio es como una burbuja para mi, esto es una burbuja. Porque esto me ha sacado de muchos problemas, me ha desconectado mucho de ellos. Le llamo burbuja al centro porqué cuando sales hay otro ambiente, esto es, otra vida." (Jonny, pseudônimo de um dos ginastas seniores. Nota extraída do Diário de Campo).

$\mathrm{O}$ isolamento produzido pelo Ginásio não é um fenômeno contemporâneo. Francisco Amorós e seus colaboradores defendiam, desde o principio do reinado dos Ginásios, como espaço ideal para o adestramento corporal e moral do homem (soldado, obreiro ou esportista, a importância de que a sala tivesse esta característica, protegendo e defendendo seus membros das "tentações" do mundo exterior e ao mesmo tempo fazendolhes submergir nos valores da cultura militar ${ }^{26}$. Uma posição semelhante à defendida pelo exército na atualidade ${ }^{27,28}$. A tranqüilidade desejada pelos fundadores do império dos Ginásios fechados segue cobrando vida na sala que tivemos a oportunidade de estudar. Este "isolamento", na opinião das pessoas que dão vida a este espaço representa um aspecto positivo que torna possível o desenvolvimento normal das atividades de treinamento, mesmo ao tornar-se uma situação dificil de assimilar e que provoca um grande impacto na personalidade dos internos considerando as necessidades humanas de relação com 
A ginástica artística masculina (GAM) de alto rendimento: observando a cultura de treinamento desde dentro.

Marco Antonio Coelho Bortoleto

o mundo exterior. Por tudo isso, podemos dizer que a domesticação do homem esportista, neste caso do ginasta, se faz também pela delimitação do espaço, pela instauração de um "ghetto" ou de um "círculo seleto" de pessoas, protegido contra as interferências do mundo exterior e que evolui a partir de "unas experiencias producidas dentro del propio grupo", segundo nos contaram os protagonistas.

Um século e meio depois da aparição dos primeiros ginásios para o "adestramento militar" 29 , nos deparamos com uma realidade na qual o Ginásio continua sendo um espaço regido pelos valores da centenária cultura ginástica. As raízes militares desde tipo ambiente ainda sustentam a dinâmica de funcionamento do Ginásio do CAR, e conseqüentemente as atividades no seu interior continuam marcadas pela repetição incansável, pela luta contra a preguiça, e pela necessidade de vencer os limites.

O treinamento brinda diariamente uma homenagem à disciplina que envolve a ginástica desde seu nascimento, controlando o espaço, o tempo, os corpos e as condutas de forma estrita, da mesma forma que observou Bailleau ${ }^{30}$ na Ginástica Rítmica.

Tudo isso nos leva a relembrar que a origem deste esporte se embasou nos princípios da educação marcial, nutrindo-se da pedagogia militar e da racionalização. Um modelo que, conforme pudemos comprovar "in situ", continua imperando apesar da "desmilitarização" que viveu o esporte ao longo do século $\mathrm{XX}^{31}$. Estes argumentos se ilustram mais claramente quando testemunhamos como alguns aparelhos usados na preparação dos ginastas, como a corda fixada no teto da sala, os espaldares ou o próprio cavalo com alças (inspirado no animal símbolo do adestramento marcial), resistiram ao passo do tempo, tratando de mostrar à modernidade que parte fundamental da essência da ginástica é o conservadorismo, ou seja, a importância da tradição e de um trabalho fundamentado por um método consolidado e respaldado pela experiência acumulada.

Contrapondo o notório avanço tecnológico vivido nos últimos 50 anos pela GAM (tanto a nível material como técnico), que teve como expoente máximo a invenção das "plataformas" modernas de salto, a cultura de preparação ginástica vivida dentro do Ginásio estudado manteve diversas características típicas da cultura militar. A titulo ilustrativo podemos mencionar alguns resquícios da formalidade marcial especialmente referente ao trato (relação) interpessoal, como por exemplo, o comprimento (saudação) "espontâneo" (um aperto de mãos) que os ginastas realizam ao cruzar com um companheiro mais velho ou com um técnico, ou na necessidade de solicitar a autorização do técnico para poder exercitar-se, beber água ou ir ao banheiro (casa de banho). Apesar de que utilizamos o termo "espontâneo", o comprimento que realizam os ginastas respeito aos técnicos e/ou a seus companheiros mais velhos parece ter muito pouco de espontaneidade, sendo um comportamento que obedece a uma regra (pacto oral) "imposta abertamente" na sala, conforme afirma um dos técnicos ao ser entrevistado. Lembramos que os militares são obrigados a cumprimentar (ou reverenciar) os mandos e as autoridades de maior graduação, um comportamento semelhante ao observado na sala ${ }^{28}$. Mencionar também que, "contrato social" é um termo inspirado em Rousseau, uma normativa oral que organiza a atividade na sala e que deve ser obedecida de maneira estrita.

Esta pesquisa também revela que o treinamento consiste num processo altamente individualizado, embasado na reprodução obediente e pouco reflexiva, sob um modelo "impositivo" de ensino (inspirado na terminologia de Muska Mosston), uma estratégia empregada nos contextos militares descritos por Zulaika ${ }^{28}$ e Anta ${ }^{27}$. 
Finalmente, comentar que a labor dos treinadores, representa uma verdadeira pedagogia da conduta motora (termo cunhado por Pierre Parlebas), concentrando todos seus esforços em aproximar a conduta motora dos ginastas aos estereótipos motores que estabelece o regulamento da GAM. Uma formação que modificará para sempre a personalidade de todos os implicados neste processo e que pode inclusive, desde a perspectiva competitiva, hiper-especializar os ginastas em um ou dois aparelhos seguindo a tendência deste esporte na atualidade.

\section{Discussão}

“Los gimnastas se preparan para ser máquinas. Para ser buenos gimnastas cuando más máquinas mejor. No hay que tomar decisiones, no hay que pensar, hay que reproducir un mismo patrón técnico de movimiento. Cuanto más exacto lo vas haciendo en el entrenamiento mejor, más parecido al patrón; siempre igual" (Joaquim, psicólogo).

Depois de séculos de evolução, o Ginásio continua sendo um contexto fundamental e legítimo para a prática da GAM, um espaço encarregado de preservar a hegemonia e a tradição do sistema de valores que formam a cultura ginástica. Obviamente devemos considerar que vivemos novos tempos, com distintas ofertas esportivas, expectativas sociais também diferentes, rápidos avanços tecnológicos e uma importante evolução da cultura esportiva em geral, e, por estes motivos, os espaços fechados, como é o caso do Ginásio do CAR de Sant Cugat, resultam pouco atrativos, e talvez uma barreira para o processo de incorporação de novos adeptos, como já mencionamos.

Isto não significa que negamos a conveniência e a idoneidade do Ginásio como espaço destinado à prática da GAM. Obviamente somos conscientes que a lógica deste esporte exige que os ginas- tas treinem diariamente em condições excelentes, com certa reserva de intimidade e tranqüilidade, algo que o Ginásio oferece sem sombra de dúvida. No entanto, para aqueles ginastas que freqüentam a sala diariamente se poderia, por exemplo, programar alguns treinamentos fora da sala, em espaços abertos, com outro ambiente e com estímulos motivacionais novos, atividades que em Sant Cugat os técnicos começam a realizar com êxito, ainda que em menor quantidade da que acreditamos necessária.

A pesar que a direção impositiva vêm sendo hegemônica até este momento na forma de conduzir os treinamentos ginásticos, entendemos que se poderia lograr uma melhor comunicação entre os protagonistas, estimulando as situações reflexivas e a conscientização da lógica de todo o processo ao que estão submetidos e suas conseqüências. Em sumo, defendemos que podem existir sistemas de treinamento mais flexíveis, ao menos nos aspectos comunicativos, que permitam certas atitudes reflexivas (mais humanas, sensíveis e menos mecânicas-racionais), que logrem os mesmos resultados que o modelo impositivo vem conseguindo atualmente.

Vimos que a carga simbólica que ressalta a cultura ginástica é uma autêntica homenagem a tradição, ao conservadorismo e a formalidade. O treinamento é uma prática engendrada pela razão, influenciada pelo conhecimento científico, que modela a motricidade dos ginastas de forma positiva, que pretende construir um corpo musculoso, um homem máquina e ao mesmo tempo elegante.

Para concluir queremos dizer que num futuro próximo pretendemos seguir aperfeiçoando este "modelo de leitura e compreensão" da cultura de treinamento da GAM e posteriormente poder aplicá-lo em Ginásios de diferentes localidades e/ ou países e assim estabelecer comparações com a realidade que acabamos de apresentar. Também 
A ginástica artística masculina (GAM) de alto rendimento: observando a cultura de treinamento desde dentro. Marco Antonio Coelho Bortoleto

vislumbramos a possibilidade de estudar este fenômeno em distintos níveis de prática, como por exemplo no esporte de base, e também na modalidade feminina, para poder estabelecer diferentes tipos de comparações e paralelismos.

\section{Correspondência:}

Marco Antonio Coelho Bortoleto

Rua Domingos Bonato, 57b

Jardim Santa Genebra II

Campinas - SP - CEP: 13084-785 - Brasil 


\section{Referências}

1. Geertz, C. (1989b). La interpretación de las culturas. Editora Gedisa, Barcelona.

2. Smoleuskiy, V. e Gaverdouskiy, I. (1991). Tratado General de Gimnasia Artística Deportiva. Editora Paidotribo, Barcelona: 22.

3. Medina, F. X. e Sánchez, R. (eds.) (2003). Culturas en juego: ensayos de antropología del deporte en España. Instituto Catalão de Antropologia (ICARIA), Barcelona: 31 .

4. García Ferrando, M., Puig, N. e Lagardera, F. (org.) (2002). Sociología del deporte. $2^{\circ}$ edição actualizada, Editora Alianza, Madrid.

5. Acuña, A. D. (1994): Fundamentos socioculturales de la motricidad humana y el deporte. Universidad de Granada, Granada.

6. Rodríguez, G. G. et. al. (1996): Metodología de la Investigación Cualitativa. $2^{\circ}$ ed., Editora Aljibe, Archidona (Málaga): 23.

7. Blanchard, K., e Taylor,A. C. (1986): Antropología del deporte. Editora Bellaterra, Barcelona.

8. Ogbu, John U. (1981). Etnografia escolar: una aproximación a nivel múltiple. Anthropology and Education Quarterly,Vol. XII, nº 1:3-29.

9. Wolcott, H. F. (1985): Sobre la intención Etnográfica. Revista Educational Administration Quarterly,Vol. XXI, n 3: 187-203.

10. Wilcox, K. (1982). La etnografía como una metodología y su aplicación al estudio de la escuela: una revisión. In Spindler, G. (1982): Doing the Ethnography of Schooling. Educational Anthropology in Action, Holt, Rinehart and Winston, NY: 465-488.

11. Woods, P. (1986). La escuela por dentro: La etnografia en la investigación educativa. Editora Paidós, Barcelona.

12. Woods, T. S. (1998). Investigación Etnográfica en la escuela. Editora Paidos, Madrid.
13. Elias, N. (1987): El proceso de la civilización. Investigaciones sociogenéticas y psicogenéticas, México, DF.

14. André, M. D. A. (1995): Etnografia da Prática Escolar. Editora Papirus, Campinas.

15. Mata, D. (2001): Hacia una especialización en antropología de campo: la etnografía del deporte. Revista Apunts, INEFC Barcelona, n. 63, p.6-14. 16. Triviños, A. S. (1992): Introdução à Investigación em Ciências Sociais: A Investigación Cualitativa em Educação; O Positivismo, A Fenomenologia e o Marxismo. Editora Atlas, São Paulo.

17. Geertz, C. (1989a). El antropólogo como autor. Editora Paidós Ibéria, Barcelona.

18. Lüschen, G. e Weis, K. (1976). Sociología del deporte. Editora Miñon, Valladolid.

19. Anzieu, D. e Martin, J. (1971). La dinámica de los grupos pequeños. Editora Kapelusz, Buenos Aires.

20. Féderation International de Gymnastique (FIG) (1985). Symposium International Sur Le Jury. FIG, Roma, junho: 24-26.

21. Leglise, M. (1985). Some medical observations on the development of high level gymnastics. Revista World Gymnastics, FIG and AIPS Press, Budapest, n. 23: 27.

22. Wacquant, L. J. (1995). Protección, disciplina y honor. Una sala de boxeo en el ghetto americano. Tese de doutorado, University of Berkeley: 9.

23. Morris, D. (1982): El deporte rey. Editora Argos Vergara, Barcelona: 19, 31.

24. Padiglione,V. Antropología del deporte y del ocio. In: Prat, J. e Martínez, A. (1996). Ensayos de antropología Cultural. Editora Ariel, Barcelona: 395-405.

25. Bortoleto, M. A. C. (2004). La lógica interna de la Gimnasia Artística Masculina (GAM) y estudio etnográfico de un Gimnasio de alto ren- 

de Lleida.

26. Soares, C. L. (1994). Educação Física - Raízes Européias e Brasil. Editora Autores Associados, Campinas.

27. Anta, J. F. (1990). Cantina, garita y cocina: Estudio antropológico de soldados y cuarteles. Editora Siglo XXI, Madrid.

28. Zulaika, J. (1989). Chivos y soldados: la mili como ritual de iniciación. La primitiva Casa Baroja, Madrid.

29. Soares, C. L. (1998). Imagens da Educação no Corpo. Autores Associados, Campinas.

30. Bailleau, L. (2004). La construction de l'Ensemble France, approche ethnographique en gymnastique rythmique. Anais do 4. Colloque International de 1'Afraga. Universidad de Picardie, Amiens: 26.

31. Simonet, P. et. al (2003). L'empreinte de Joinville: 150 ans de sport 1852-2002. INSEP, Paris.

32. Bailleau, L. (2001). La culture gimnique: une ethnographie d'un groupe de haut niveau. Dissertação de mestrado. Universidade de Orleans.

33. Mata, D. (2004). Un estudio etnográfico sobre el voley playa. Revista Apunts Educación Física, INEFC Barcelona, $n^{\circ}$. 75, Barcelona, p. 519.

34. Rubio, K. (2001). O atleta e o mito do herói: o imaginário esportivo contemporáneo. São Paulo, Editora Casa do Psicólogo.

35. Generalitat de Catalunya (2003). Catalunya, un país esportiu. Generalidad de Cataluña, Departamento de Cultura, Barcelona. 